\title{
GRAVIDEZ, PUERPÉRIO E DOENÇA VASCULAR CEREBRAL
}

\author{
MARCIA MAIUMI FUKUIMA*, ROBERTO DE MAGALHÃES CARNEIRO DE OLIVEIRA*, \\ JEAN CARLOS SHIMAZAKI**, JOSÉ GERALDO DE CAMARGO LIMA***
}

RESUMO - Foram estudadas seis pacientes com doenças cerebrovasculares no periodo gravidico-puerperal. Uma apresentou hemorragia cerebral, três apresentaram infarto cerebral e duas trombose de seio venoso cerebral. A associação de fatores clinicos ao estado peculiar produzido pela gravidez parece ter resultado nas doenças apresentadas, com especial ênfase à doença de Chagas presente em todos os infartos cerebrais.

PALAVRAS CHAVE: gravidez, puerpério, acidente vascular cerebral, infarto cerebral, hemorragia cerebral, trombose venosa cerebral, doença de Chagas.

\section{Pregnancy, puerperium and cerebrovascular disease}

ABSTRACT - Six patients who presented cerebrovascular disease during puerperium or pregnancy were studied. One of them presented hemorrhagic stroke caused by intracerebral bleeding due to pre-eclampsia. Three patients presented ischemic stroke, they all had positive serologic reactions for Chagas' disease, but only two of them had clinical cardiopathy; one of these patients had anticardiolipin antibody. The other two patients presented cerebral venous thrombosis of sagittal sinus. Both were smokers and one of them used oral contraceptive. We emphasize the importance of clinical investigation to seek for the common causes of cerebrovascular disease in young people, with special attention to Chagas disease in Brazil.

KEY WORDS: pregnancy, puerperium, stroke, cerebral infarction, cerebral hemorrhage, cerebral venous thrombosis, Chagas' disease.

No período gravidico-puerperal, isto é, do início da gestação até 90 dias após o parto, ocorre uma série de alterações na fisiologia materna, que podem resultar em complicações neurológicas, dentre elas, fenômenos vasculares cerebrais. Estes representam 4 a $8 \%$ dos óbitos maternos; este indice vem crescendo relativamente devido ao declínio da mortalidade por causas obstétricas ${ }^{12}$. Sabe-se que nesse periodo o risco de acidente vascular cerebral isquêmico (AVCI) aumenta até 13 vezes; no entanto, a incidência não é bem definida, variando de 1 em 26000 a 1 em 481 gestaçðes 2.3.8.13.13. Nesse período ocorrem classicamente as tromboses de seios venosos cerebrais (TVC), com predominio no puerpério ( $95 \%$ da $l^{*}$ à 5 semanas após o parto), enquanto os infartos por oclusão arterial predominam nos $2^{\circ}$ e $3^{\circ}$ trimestres da gestação (cerca de $60 \%$ ). A incidência de TVC varia de 1 em 10000 a 1 em 2500 gestações, com mortalidade que vem decrescendo de $30 \%$ a $5,5 \%$ nos últimos anos devido a maior precisão diagnóstica e tratamento precoce ${ }^{1,4,16}$. A incidência de hemorragia cerebral intraparenquimatosa $(\mathrm{AVCH})$ varia de 1 a $5 \mathrm{em} 10000$ gestações, com mortalidade de 30 a $40 \%{ }^{17}$.

Esses fenômenos vasculares cerebrais durante o periodo gravidico-puerperal requerem especial atenção tanto do neurologista quanto do obstetra, com o intuito de proporcionar as melhores condiçðes possiveis para o feto e minimizar as sequelas maternas, como se mostra nesta casuística.

Estudo reaizado na Escola Paulista de Medicina (EPM) da Universidade Federal de São Paulo (UNIFESP): *Mestre em Neurologia pela EPM-UNIFESP; **Neurologista pela EPM-UNIFESP; ***Professor Titular e Chefe da Disciplina de Neurologia da EPM-UNIFESP. Aceite: 12-dezembro-1995. 


\section{CASUÍSTICA}

Apresentamos os dados de 6 pacientes atendidas ambulatorialmente pelo Setor de Doenças Neurovasculares da EPM no ano de 1992. Todas estavam no periodo gravidico-puerperal. Foram submetidas ao protocolo de investigação etiológica de acidente vascular cerebral, que inclui pesquisa de causas cardíacas, reumatologicas e hematológicas, entre outras, e acompanhadas por periodo médio de 360 dias.

Apresentamos sucintamente os casos nas Tabelas 1, 2 e 3.

Tabela I. Idade, idade gestacional ou de puerpério, quadro clinico e antecedentes pessoais.

\begin{tabular}{|c|c|c|c|c|}
\hline Paciente & Idade & $\begin{array}{l}\text { Idade gestacional } \\
\text { ou de puerpério }\end{array}$ & Quadro clínico & Antecedentes Pessoais \\
\hline 1 & 32 & 38 sem de gestação & $\begin{array}{l}\text { pré-eclâmpsia + cefaléia súbita } \\
\text { + hemipareisa } \mathrm{E}+\text { disartria }\end{array}$ & Tabagismo \\
\hline 2 & 26 & $5 \mathrm{~d}$ de puerpério & Hemiparesia D + afasia mista & - \\
\hline 3 & 23 & $18 \mathrm{~d}$ de puerpério & Cefaléia súbita + hemiparesia $\mathrm{E}$ & - \\
\hline 4 & 30 & $60 \mathrm{~d}$ de puerpério & $\begin{array}{l}\text { Hemiparesia D + hipoestesia D + } \\
\text { afasia de expressão }\end{array}$ & $\begin{array}{l}\text { Doença de Chagas } \\
\text { com marca-passo cardiaco } \\
\text { e uso de anti-arrítmico }\end{array}$ \\
\hline 5 & 33 & $30 \mathrm{~d}$ de puerpério & $\begin{array}{l}\text { Cefaléia + vômitos }+ \\
\text { papiledema bilateral }\end{array}$ & $\begin{array}{l}\text { Uso de anticoncepcional } \\
\text { oral }+ \text { tabagismo }\end{array}$ \\
\hline 6 & 34 & $1 \mathrm{~d}$ de puerpério & $\begin{array}{c}\text { Cefaléia + hemiparesia } \mathrm{E}+ \\
\text { papiledema bilateral }\end{array}$ & Tabagismo \\
\hline
\end{tabular}

sem, semanas; d, dias; D, direita; E, esquerda.

Tabela 2. Exames subsidiários.

\begin{tabular}{|c|c|c|c|}
\hline Paciente & Tomografia & Angiografia & Outros \\
\hline 1 & Hematoma cápsulo-nuclear à D & Normal & - \\
\hline 2 & Infarto fronto-parietal a $\mathrm{E}$ & - & $\begin{array}{l}\text { Sorologia positiva para Chagas + } \\
\text { ECG normal; Ecocardiograma normal }\end{array}$ \\
\hline 3 & Infarto cápsulo-nuclear à D & - & $\begin{array}{c}\text { Sorologia positiva para Chagas + ECG: } \\
\text { bloqueio do ramo direito; Ecocardiograma: } \\
\text { discreto aumento de ventrículo } E \text {; anticorpo } \\
\text { anticardiopina IgM=1/50 }\end{array}$ \\
\hline 4 & Infarto fronto-parietal à $\mathrm{E}$ & - & $\begin{array}{l}\text { Sorologia positiva para Chagas }+ \\
\text { Ecocardiograma: aumento importante do átrio } \\
\text { e ventrículo } \mathrm{E} \text {, hipocinesia do ventriculo } \mathrm{E} \text {, } \\
\text { sem trombos intracavitários }\end{array}$ \\
\hline 5 & Sinal do delta vazio & Oclusão do seio sagital & superior \\
\hline 6 & Infarto parieto-occipital à D & $\begin{array}{l}\text { Oclusão do seio sa } \\
\text { superior e sinuso }\end{array}$ & $\begin{array}{l}\text { gital } \\
\text { dal }\end{array}$ \\
\hline
\end{tabular}

$D$, direita; $E$, esquerda. 
Tabela 3. Diagnóstico, tratamento e evolução.

\begin{tabular}{|c|c|c|c|}
\hline Paciente & Dianóstico & Tratamento & Evolução \\
\hline 1 & $\mathrm{AVCH}$ & $\begin{array}{l}\text { Anti-hipertensivo (nifedipina) } \\
\text { por } 3 \text { meses }\end{array}$ & $\begin{array}{l}\text { Normalizaçðo do quadro } \\
\text { neurológico em } 12 \text { meses }\end{array}$ \\
\hline 2 & AVCl & $\begin{array}{l}\text { Antiagregante plaquetário } \\
\text { (ácido acetil salicilio) }\end{array}$ & $\begin{array}{l}\text { Linguagem normal em } 2 \text { meses, } \\
\text { persiste com déficit motor }\end{array}$ \\
\hline 3 & AVCl & $\begin{array}{l}\text { Antiagregante plaquetário } \\
\text { (ácido acetil salícilico) }\end{array}$ & Discreta melhora do deficit motor \\
\hline 4 & AVCI & $\begin{array}{l}\text { Anticoagulante oral } \\
\text { (warfarina) }\end{array}$ & $\begin{array}{l}\text { Discreta melhora do déficit motor } \\
\text { persiste com afasia de expressac }\end{array}$ \\
\hline 5 & TVC & $\begin{array}{c}\text { Anticoagulante oral } \\
\text { (warfarina) por } 6 \text { meses }\end{array}$ & Assintomática em 1 mês \\
\hline 6 & TVC & $\begin{array}{l}\text { Anticoagulante oral } \\
\text { (warfarina) por } 6 \text { meses }\end{array}$ & $\begin{array}{l}\text { Melhora importante; porém } \\
\text { mantém discreto déficit motor }\end{array}$ \\
\hline
\end{tabular}

AVCH, acidente vascular cerebral hemorrágico; AVCl, acindente vascular cerebral isquêmico; TVC, trombose venosa cerebral.

\section{DISCUSSĀOO}

As principais complicaçð̃es cerebrovasculares que ocorrem no período gravídico-puerperal são as apresentadas pelas pacientes relatadas.

Chamou-nos a atenção a presença de fatores associados nos casos de AVCI. As três pacientes com AVCI tinham sorologia positiva para doença de Chagas, porém apenas duas apresentavam alteraçð̌es ao ECG e ecocardiogräficas; uma delas apresentou anticorpo anti- cardiolipina. As duas pacientes com trombose de seio cerebral eram tabagistas, e uma delas usuária de anticoncepcional oral.

As causas de oclusão arterial na gestação não diferem daquelas dos adultos jovens em geral. Porém, nesse período, há um estado peculiar de hipercoagulabilidade que ocorre devido ao aumento dos níveis de fibrinogênio e fatores de coagulação V, VII, VIII, IX, X e XII, redução dos niveis de antitrombina III e da atividade do plasminogênio tissular, redução dos niveis de proteina $\mathrm{S}$ e aumento da agregabilidade plaquetária ${ }^{5,8}$. As oclusões arteriais tendem a ocorrer durante o segundo e terceiro trimestre de gravidez e durante a primeira semana de puerpério ${ }^{3,12}$. Na amostra apresentada, todas ocorreram no puerpério (Tabela 1 - Pacientes 2, 3 e 4). Apesar de 20 a $25 \%$ das oclusões arteriais em gestantes permanecerem sem diagnóstico mesmo após avaliação extensa, ressaltamos a importância da investigação adequada desse grupo de doenças no referido período, incluindo fatores próprios dessa fase, bem como fatores de risco conhecidos para doenças vasculares cerebrais. Estes fatores incluem pesquisa de causas cardíacas: embolia relacionada às válvulas cardíacas (endocardite infecciosa, febre reumática), trombose intracardiaca (fibrilação atrial, cardiomiopatia gravidica), tromboembolismo venoso sistêmico com forame oval patente ${ }^{4.14} \mathrm{e}$ em nosso meio, a doença de Chagas, causadora de cardiomiopatia com dilatação, por vezes com aneurisma de parede ventricular e arritmia. Doenças que acometem os vasos da região cervical devem ser pesquisadas: aterosclerose (por hipertensão, diabetes melito, hiperlipidemia, tabagismo, radioterapia), doença de Takayassu, displasia fibromuscular, dissecção espontânea da carótida, além das doenças que acometem os vasos intracranianos (vasculites por colagenoses, uso de drogas como cocaína, ou infecçóes) ${ }^{14,16} . \mathrm{O}$ mecanismo hemodinâmico para AVCI também deve ser considerado, pois pode haver grande sangramento durante o parto ${ }^{16}$. Pesquisa de anticorpos antifosfolipídicos deve ser realizada assim como perfil reumatológico e pesquisa de doenças hematológicas pró-trombóticas (anemia falciforme, púrpura trombótica trombocitopênica, deficiência congênita de antitrombina III, proteína C e proteína S) ${ }^{4,6,9}$. O conjunto destes fatores parece ter importância para a instalação dessas doenças. Causas raras também são referidas: embolia de liquido amniótico, gás ou gordura ${ }^{16.11}$. 
As oclusões venosas, por sua vez, tendem a ocorrer da primeira à quarta semana de puerpério, como ocorreu nos casos apresentados. As localizações mais comuns da TVC no ciclo gravídicopuerperal são o seio sagital superior com extensão secundária para as veias corticais, e as veias corticais primariamente envolvidas. Costumam manifestar-se por cefaléia resistente a analgésicos, acompanhada de vômitos, visão turva ou diplopia, crises epilépticas parciais ou generalizadas, assim como déficits neurológicos focais ${ }^{7}$. O trombo do seio sagital pode evoluir com obstrução dos vilos aracnóides, bloqueando o fluxo de líquido cefalorraquidiano, causando hipertensão intracraniana. $A$ oclusão das veias corticais produz isquemia e edema cerebral focais que evoluem com infarto cerebral hemorrágico. Apesar de não se encontrar outras etiologias na maioria dos casos de TVC no periodo gravídico-puerperal, além da perda súbita de volemia durante o parto e do estado pré-trombótico, devem ser excluidas: infecçðes, síndromes de hiperviscosidade como anemia falciforme, leucemia e policitemia vera, hemoglobinúria paroxística noturna, síndrome do anticorpo antifosfolipide, malignidade e malformações arteriovenosas. Apesar da alta mortalidade ( 5,5 a $30 \%$ ), o prognóstico para os sobreviventes é relativamente bom, com somente 10 a $20 \%$ de déficits neurológicos persistentes $^{1,16}$. As Pacientes 5 e 6 da nossa série, como pode ser visto na Tabela 3, evoluíram bem com terapia de anticoagulação oral.

Hipertensão arterial é o fator de risco mais importante para $\mathrm{AVCH}$, tanto em gestantes como na população geral. Na gravidez temos que ressaltar que, mesmo não havendo hipertensão, ocorrem aumento da volemia e pressão venosa; durante o trabalho de parto o débito cardíaco aumenta com consequente aumento da pressão intracraniana, que se acentua na manobra de Valsalva, predispondo ao AVCH. Além disso, há condições próprias da gravidez, como eclâmpsia, coriocarcinoma metastático e coagulação intravascular disseminada ${ }^{10}$, que propiciam o sangramento intracraniano. O estrogênio elevado tem papel de dilatar vasos anormais durante a gravidez, talvez incluindo estruturas vasculares cerebrais como malformações arteriovenosas e fístula carotidocavernosa, predispondo ao seu sangramento. Outras causas de AVCH que devem ser pesquisadas incluem: abuso de cocaina e álcool, metástases de coriocarcinoma, doença de moya-moya, sarcoma de Kaposi e síndromes hemorrágicas. A topografia do AVCH em gestantes não difere da população de hipertensos, ocorrendo preferencialmente nos gânglios da base, tálamo, cerebelo e ponte ${ }^{17}$, como pode ser constatado na Paciente 1 da nossa série (Tabela 2).

\section{REFERÊNCIAS}

1. Ameri A, Bousser MG. Cerebral venous trhombosis. Neurologic Clinics 1992;10:87-111.

2. Banerjee AK, Varma M, Vasista RK, Chopra JS. Cerebrovascular disease in north-west India: a study of necropsy material. J Neurol Neurosurg Psychiatry 1989;52:512-515.

3. Bevan H, Sharma K, Bradley W. Stroke in young adults. Stroke 1990;21:382-386.

4. Donaldson JO, Lee NS. Arterial and venous stroke associated with pregnancy. Neurologic Clinics 1994;12:583-599.

5. Finley BE. Coagulopatia aguda no gravidez. Clinicas Médicas da America do Norte 1989;73: 793-814.

6. Futrell N, Millikan C. Neurologic disorders of pregnancy: connective tissue. Neurologic Clinics 1994;12:527-539.

7. Hainline B. Neurologic complications of pregnancy: headache. Neurologic Clinics 1994;12:443-460.

8. Holcomb WL Jr, Petrie RH. Cerebrovascular emergencies in pregnancy. Clin Obstetr Gyn 1990;33:467-472.

9. Lockwood CJ, Rand JH. The immunobiology and obstetrical consequences of antiphospholipid antibodies. Obst Gyn Survey 1994;49:432-441.

10. Raps EC, Galetta SL, Broderick $M$, Atlas SW. Delayed peripartum vasculopathy: cerebral eclampsia revisited. Ann Neurol 1993;33:222-225.

11. Sharshar T, Lamy C, Mas JL. Incidence and causes of strokes associated with pregnancy and puerperium: a study in public hospitals of lle de France. Stroke 1995;26:930-936.

12. Simolke GA, Cox SM, Cunningham G. Cerebrovascular accidents complicating pregnancy and the puerperium. Obstetr Gynecol 1991;78:37-42.

13. Srinivasan $K$. Ischemic cerebrovascular disease in the young: two common causes in India. Stroke 1984;15:733-737.

14. Wieber DO. Ischemic cerebrovascular complications of pregnancy. Arch Neurol 1985;12:1106-1113.

15. Wiebers DO, Whisnant JP. The incidence of stroke among pregnant women in Rochester, Minn, 1955 through 1979. JAMA 1985;254:3055-3057.

16. Wilterdink JL, Easton JD. Cerebral ischemia. In Devinsky O, Feldmann E, Hainline B. Neurological complications of pregnancy. New York: Raven Press, 1994: 1-11.

17. Wilterdink JL, Feldmann E. Cerebral hemorrhage. In Devinsky O, Feldmann E, Hainline B (eds). Neurological complications of pregnancy. New York: Raven Press, 1994: 13-23. 